\title{
Comparison of quantitative genetic variation and allozyme diversity within and between populations of Scabiosa canescens and S. columbaria
}

\author{
PATRIK WALDMANN* \& STEFAN ANDERSSON \\ Department of Systematic Botany, University of Lund, Östra Vallgatan 18-20, 22361 Lund, Sweden
}

\begin{abstract}
We quantified allozyme diversity and quantitative genetic variation within and between six populations of the locally rare Scabiosa canescens and the more common and widespread $S$. columbaria (Dipsacaceae). For the within-population component, we quantified allozyme diversity as the expected heterozygosity $\left(H_{\mathrm{e}}\right)$, followed by a sib analysis to estimate the heritability $\left(h^{2}\right)$ for eight vegetative and floral characters. There was no consistent association between $h^{2}$ and $H_{\mathrm{e}}$, or between $h^{2}$ and current population size. Regarding the betweenpopulation component, we compared the overall level of population differentiation for the allozymes $\left(F_{\mathrm{ST}}\right)$, assumed to be selectively neutral, with the corresponding estimates for the quantitative traits $\left(Q_{\mathrm{ST}}\right)$ to determine if the marker genes and the polygenic characters have been influenced by the same evolutionary force(s). Differences between estimates of $F_{\mathrm{ST}}$ and $Q_{\mathrm{ST}}$ for $S$. canescens were too small to be declared as significant, indicating that neutral phenotypic evolution has led to the observed differentiation in this species. Our data indicate higher levels of phenotypic differentiation in $S$. columbaria with values of $Q_{\mathrm{ST}}$ exceeding the allozymic $F_{\mathrm{ST}}$ for all traits. This finding indicates a great potential for $S$. columbaria to respond to local selection pressures, perhaps explaining why this species has a broader ecological amplitude than $S$. canescens.
\end{abstract}

Keywords: allozymes, genetic diversity, population differentiation, quantitative genetics, rarity, Scabiosa.

\section{Introduction}

Heritable variation is necessary for adaptation and long-term survival of populations in a changing environment (Falconer, 1989) and has become a major topic in conservation biology (Schemske et al., 1994), even though demographic data are considered more useful for monitoring and managing populations in the short term (Lande, 1988). Genetic studies of rare and declining species usually focus on allozymes or molecular marker genes, whereas few attempts have been made to assess patterns and amounts of heritable variation in ecologically important characters controlled by a large number of loci (Widén \& Andersson, 1993; Schemske et al., 1994; Storfer, 1996).

\footnotetext{
*Correspondence. E-mail: patrik.waldmann@sysbot.lu.se
}

This focus on marker genes has several limitations if the aim is to provide information on adaptation and long-term survival of populations (Lynch, 1996). First, the presumably high mutation rate of quantitative characters (Falconer, 1989) suggests that the recovery time after a bottleneck will be shorter for polygenic variation than for single-locus polymorphisms (Lande \& Barrowclough, 1987). Secondly, the expected loss of additive genetic variance caused by genetic drift does not follow the same pattern as the reduction in single-locus heterozygosity when there are high levels of nonadditive genetic variance in the character (Goodnight, 1988; Willis \& Orr, 1993). Thirdly, the effect of small population size on genetic variation is expected to differ for monogenic and polygenic characters as a result of selection acting differently on these types of character (Foley, 1992). These differences suggest that conservation 
strategies based solely on the variation at marker gene loci may be misleading and that quantitative genetic analyses therefore serve as an important complement in studies of rare and threatened species (Lande \& Barrowclough, 1987; Lynch, 1996; Storfer, 1996).

Genetic variation not only contributes to differences between individuals within populations, but also accounts for differences between populations. As for adaptive traits with a polygenic basis, the proportion of variation within a population attributable to the additive effects of genes can be quantified as the heritability (Falconer, 1989). Regarding the between-population component, it is desirable to quantify the level of population subdivision of quantitative characters in a form that allows direct comparison with the presumably neutral marker genes. For example, to examine whether single-locus and polygenic characters are influenced by the same evolutionary force(s), it may be useful to compare estimates of the population structure based on Wright's (1951) $F$-statistics (Spitze, 1993; Podolsky \& Holtsford, 1995; Yang et al., 1996). In this approach, diversifying selection may be invoked when the level of population differentiation in a quantitative character (hereafter referred to as $Q_{\text {ST }}$ following Spitze, 1993) is significantly higher than the corresponding parameter for the marker genes $\left(F_{\mathrm{ST}}\right)$, whereas unifying selection may be invoked when $Q_{\mathrm{ST}}$ is significantly lower than $F_{\mathrm{ST}}$. If the estimates of $Q_{\mathrm{ST}}$ and $F_{\mathrm{ST}}$ are similar, the hypothesis that the population structure of the quantitative trait is caused by random drift cannot be rejected (Spitze, 1993; Podolsky \& Holtsford, 1995; Yang et al., 1996).

In the present investigation of Scabiosa canescens and $S$. columbaria, we quantified levels of variation between and within populations to determine whether the heritability of quantitative characters is correlated with allozyme diversity and population size, and whether allozymes and polygenic traits have been influenced by the same evolutionary force(s). Comparison of the locally rare $S$. canescens and the more common $S$. columbaria also provided an opportunity to assess the relationship between rarity and quantitative genetic variation.

\section{Materials and methods}

Scabiosa columbaria L. and S. canescens W. \& K. (Dipsacaceae) are diploid $(2 n=16)$, perennial plants with basal leaf rosettes, a variable number of branched stems with a determinate flowering pattern and blue, bilabiate, protandrous, self-compatible and outcrossing flowers arranged in dense, terminal inflorescences (hereafter 'heads') visited by syrphids, butterflies and bees (Van Treuren et al., 1994). Fertilized flowers develop into one-seeded, indehiscent fruits ('seeds') enclosed in umbrella-shaped epicalyces crowned by spines.

Scabiosa columbaria occurs in various grassland habitats in large parts of Europe and is locally common in southern Sweden with $\approx 100$ localities in Skåne, the southernmost region. Scabiosa canescens has a more eastern distribution in Europe and occupies a much narrower range of habitats: the 25 localities in Sweden represent steppe-like sites with sandy soils in Skåne (pers. obs.).

In 1993, one of us (P.W.) selected six differentsized populations of each species in Skåne. Population size was determined by direct counts if the number of individuals was below 250, whereas the sizes of larger populations were estimated by multiplying the number of plants in a $10 \times 10 \mathrm{~m}$ square by the approximate number of squares that could be fitted by eye to the population. The populations used in the present investigation were separated from other populations by more than $1 \mathrm{~km}$ and showed a more than 100 -fold difference in population size (Table 1). Most of these populations have been relatively stable between 1993 and 1997 (unpubl. data), suggesting that differences in population size could have persisted for a long time.

One flower head with ripe seeds and one leaf rosette were collected from each of 25 randomly

Table 1 Information on the populations of Scabiosa columbaria and $S$. canescens used in the present investigation

\begin{tabular}{lllr}
\hline Species/Location & Abb. & Coord. & $N$ \\
\hline $\begin{array}{l}\text { S. columbaria } \\
\text { Smygehuk }\end{array}$ & $\mathrm{Sm}$ & 1C7i21941 & 55 \\
$\begin{array}{l}\text { Bjärred } \\
\text { Klagshamn }\end{array}$ & $\mathrm{Bj}$ & 2C6e20740 & 59 \\
Billebjär & $\mathrm{Kl}$ & 2C1e34201 & 236 \\
Grödby & $\mathrm{Bi}$ & 2C5i20938 & 600 \\
Margaretevall & $\mathrm{Gr}$ & 3E3d44146 & 1500 \\
S. canescens & $\mathrm{Ma}$ & 1D8 h21233 & 5000 \\
Hällestad & & & \\
Veberöd & $\mathrm{Hä}$ & 2C5j20046 & 25 \\
Degeberga & $\mathrm{Ve}$ & 2D3b34008 & 100 \\
Vitemölla & $\mathrm{De}$ & 2D8i10528 & 138 \\
Yngsjö & $\mathrm{Vi}$ & 2D5j21241 & 2000 \\
Àhus & $\mathrm{Yn}$ & 2E9a11620 & 4000 \\
\hline
\end{tabular}

Abb., abbreviation; Coord., RUBIN coordinates; $N$, the estimated number of flowering individuals in 1993.

(c) The Genetical Society of Great Britain, Heredity, 81, 79-86. 
selected plants in each population. The seeds were stored in separate paper bags at room temperature for later use in the quantitative genetic study (see below), and the leaf rosettes were wrapped in moist paper and placed in a portable cooling bag for transportation to a refrigerator in the laboratory $\left(4^{\circ} \mathrm{C}\right)$. Extraction was performed by grinding $\approx 1 \mathrm{~cm}^{2}$ of a leaf in $120 \mu \mathrm{L}$ of extraction buffer $(2.4 \%$ Tris, $2 \%$ polyvinylpyrollidone, $0.1 \%$ EDTA, $0.2 \% \mathrm{MgCl}_{2}, 1 \%$ sodium metabisulphite and $0.2 \%$ di-mercaptoethanol at $\mathrm{pH}$ 7.5). The tissue extracts were absorbed onto eight filter paper wicks per individual and stored at $-80^{\circ} \mathrm{C}$ until used.

Electrophoresis was carried out on $12 \%$ starch gels (Reppin PSG 1000) using two buffer systems. A morpholine-citrate buffer with $\mathrm{pH} 6.1$ (Wendel \& Weeden, 1989) was used for the following enzymes: aconitase (EC 4.2.1.3, ACO), phosphogluconate dehydrogenase (EC 1.1.1.44, PGD), phosphoglucoisomerase (EC 5.3.1.9, PGI) and shikimate dehydrogenase (EC 1.1.1.25, SKD), and a $\mathrm{LiOH}$-borate buffer with $\mathrm{pH} 8.3$ (Ashton \& Braden, 1964) was used for aspartate aminotransferase (EC 2.6.1.1, AAT), phosphoglucoisomerase (EC 5.3.1.9, PGI) and triose phosphate isomerase (EC 5.3.1.1, TPI). Hence, both buffer systems were used for the PGI system. Staining schedules were according to Wendel \& Weeden (1989). Twelve other enzyme systems were also tested, but the banding patterns of these systems were not interpretable in terms of alleles at Mendelian loci.

Deviations from Hardy-Weinberg expectation and linkage equilibrium were tested for each population using the exact tests in the GENEPOP package (Raymond \& Rousset, 1995), and the allelic diversity at polymorphic loci was quantified as the mean expected heterozygosity $\left(H_{\mathrm{e}}\right)$ with BIOsys-1 (Swofford \& Selander, 1989). To assess levels of population divergence, the global deficit of heterozygotes $\left(F_{\mathrm{IT}}\right)$ was partitioned into two components: heterozygote deficit within populations $\left(F_{\text {IS }}\right)$ and heterozygote deficit between populations ( $F_{\mathrm{ST}}$, Wright, 1951). These $F$-statistics, with $95 \%$ confidence intervals (CI) of each estimate, were quantified with FSTAT (Goudet, 1995) according to the variance component approach by Weir \& Cockerham (1984).

In May 1994, 20 seeds per plant were sown in large pots with a mixture of standard soil $(\approx 90 \%)$, sand $(10 \%)$ and lime $(1 \%)$. Some families were represented by fewer than 20 seeds, but only one family per species had to be excluded because of low seed-set. The resulting seedlings were raised under standard growth conditions and fertilized once a week. After 75 days, five randomly chosen seedlings per family were planted in separate pots and randomized in an unheated greenhouse. For some populations, it was necessary to compensate for low germination by increasing the number of seedlings from families with a high germination rate. The plants were overwintered outdoors to enhance flowering in 1995.

The following traits were scored on each individual: leaf number, length and area of the longest leaf, first flowering date, height of the main shoot, maximum plant height, number of heads and flower size. The leaf traits were measured 75 days after sowing (1994), whereas other characters were measured in the first flowering season (1995). Leaf size characters were quantified with an image analysis system (IMAGEGRABBER, OPTILAB) on a Macintosh computer. Flower size, measured under a dissecting microscope, refers to the average distance from the base of the corolla to the tips of the left and right side lobes on the lower lip (based on one marginal flower from the terminal head on each plant). Phenotypic data were obtained for a maximum of 619 and 751 plants of $S$. canescens and S. columbaria, respectively.

A variance component analysis with population and family (nested within population) as random effects was conducted for each trait and species with the REML directive in GENSTAT 5 (1995). The (average) level of genetic variance within populations $\left(V_{\mathrm{G}}\right)$ was estimated as twice the between-family variance component under the assumptions that maternal effects were weak, that offspring within families were related as full-sibs and that most of the genetic variance was additive. The betweenpopulation component ( $V_{\text {pop }}$ ) was assumed to quantify the variance attributable to heritable differences between populations.

Estimates of $V_{\text {pop }}$ and $V_{\mathrm{G}}$ were used to quantify the level of population differentiation $\left(Q_{\mathrm{ST}}\right)$ for each of the continuous characters (Wright, 1951; see also Spitze, 1993; Podolsky \& Holtsford, 1995). Provided that $V_{\text {pop }}$ and $V_{\mathrm{G}}$ have a strong additive component and that populations are in Hardy-Weinberg equilibrium $\left(F_{\mathrm{IS}}=0\right)$, it can be shown that $Q_{\mathrm{ST}}=$ $V_{\text {pop }} /\left(2 V_{\mathrm{G}}+V_{\text {pop }}\right)$. This parameter is analogous to $F_{\mathrm{ST}}$ and therefore provides an opportunity to compare population divergence in phenotypic characters and in single-locus allele frequencies. To obtain approximate $95 \%$ CI of $Q_{\mathrm{ST}}$, we used the vFUNCTION option in GENSTAT 5, a procedure based on the delta method (Kendall \& Stuart, 1969). We also employed the REML directive and the VFUNCTION procedure in GENSTAT 5 to estimate the heritability $\left(h^{2}\right)$ and the 95\% CI of $h^{2}$ for each character and population, 
calculated as twice the proportion of the variance attributable to family differences and based on the same assumptions as the estimation of $V_{\mathrm{G}}$ (see above).

Associations between population size, allozyme diversity and heritability were estimated by computing the Pearson correlation coefficient for each of 1000 bootstrap samples (Efron \& Tibshirani, 1986) with the BOOTSTRAP procedure in GENSTAT 5. The BOOTSTRAP procedure was also employed to test for differences between species in the mean heritability for each trait and for the mean heritability over traits (averaged over populations). Finally, we utilized Mantel's (1967) matrix permutation method with 2000 randomizations to test for associations between pairwise interpopulation distances based on allozymes ( $F_{\mathrm{ST}}$ values) and quantitative characters ( $Q_{\mathrm{ST}}$ values).

\section{Results}

\section{Allozymes}

Electrophoretic analyses of $S$. columbaria revealed five polymorphic loci (AAT-1:2, ACO-2:3, PGI-2:3, $P G D-2: 2$ and TPI-1:2; the first number denotes the locus and the second refers to the number of alleles found at this locus). The banding pattern of SKD could not be interpreted in terms of Mendelian loci and had to be excluded from all analyses, whereas the interpretation of $P G I-2$ and $P G D$-2 agreed with allozyme data from Van Treuren \& Bijlsma (1992). Only two variable loci (AAT-1:3, SKD-1:3) were found in $S$. canescens; the $P G D$ and TPI loci turned out to be monomorphic and the banding patterns of PGI and ACO were impossible to interpret in terms of alleles. The two species appear to have similar sets of alleles at the $A A T, P G D$ and TPI loci.

There was no significant deviation from HardyWeinberg equilibrium $(P>0.05)$ in any of the populations of $S$. canescens, and only two out of 30 comparisons (six populations $\times$ five loci) revealed a significant deviation from random mating $(P<0.05)$ in $S$. columbaria. There was no evidence for nonrandom associations of alleles between pairs of loci in $S$. canescens $(P>0.05)$ and only three out of 60 pairwise combinations of loci were found to be in significant linkage disequilibrium $(P<0.05)$ in $S$. columbaria.

The $F_{\mathrm{ST}}$-values for individual loci in $S$. columbaria ranged from 0.09 (PGI-2) to 0.15 (TPI-1), with a mean $F_{\mathrm{ST}}(0.123)$ significantly greater than 0 (CI 0.101-0.142). Although the number of polymorphic loci in $S$. canescens was too small for calculation of
CI (Goudet, 1995), the mean $F_{\text {Sт }}(0.164)$ differed significantly from 0 according to a permutation test $(P<0.001$; Fstat, Goudet, 1995). As for the withinpopulation variation, the expected mean heterozygosity $\left(H_{\mathrm{e}}\right)$ ranged from 0.18 to 0.45 for $S$. columbaria and from 0.04 to 0.39 for $S$. canescens (Table 2a,b). These data are not directly comparable for the two species, as they are based on different sets of loci. There was no significant correlation between $H_{\mathrm{e}}$ and population size $(P>0.05)$ in either of the species.

\section{Quantitative characters}

Only four plants of $S$. columbaria and 11 plants of $S$. canescens died during the winter, and nearly all surviving plants flowered in their first season (100 and $98 \%$ in $S$. columbaria and $S$. canescens, respectively). A distribution-fit-test (DISTRIBUTION directive in GENSTAT 5) showed that most of the characters were approximately normally distributed, the only exceptions being leaf number, head number and first flowering date, which had to be square root transformed to reach normality.

Population means and heritabilities $\left(h^{2}\right)$ are shown in Table 2(a,b). Populations of $S$. canescens had higher heritabilities than populations of $S$. columbaria for most of the characters: the difference reached significance for leaf area and length $(P<0.001)$ and for the average heritability $(P<0.05)$. Estimates of $h^{2}$ varied independently of $H_{\mathrm{e}}$ in both species $(P>0.05)$, the only exception being leaf area in $S$. canescens $(r=0.78, P<0.05)$. Population size was significantly negatively correlated with $h^{2}$ for leaf area, leaf length and flower size $(r=-0.65,-0.67$ and -0.67 , respectively; $P<0.05$ in all cases) in $S$. columbaria, and with $h^{2}$ for first flowering date $(r=-0.72, P<0.05)$ in $S$. canescens. The only significant positive association with population size involved $h^{2}$ for leaf number in $S$. canescens $(r=0.78, P<0.05)$. Estimates of $h^{2}$ for other characters showed a nonsignificant relationship with population size $(P>0.05)$.

Estimates of $Q_{\mathrm{ST}}$ for $S$. columbaria differed widely between traits (Table 3 ), but always exceeded the $F_{\mathrm{ST}}$ based on allozymes. In the case of flower size and plant stature, the differences were sufficiently large to be declared as significant (nonoverlapping CI). Populations of $S$. canescens showed lower levels of differentiation: none of the $Q_{\mathrm{sT}}$ estimates differed significantly from 0 and all but one (flower size) were lower than the allozymic $F_{\mathrm{ST}}$. We found no consistent association between pairwise genetic distances based on $F_{\mathrm{ST}}$ and $Q_{\mathrm{ST}}(P>0.05)$. 
Table 2(a) Population means, heritabilities and expected heterozygosities $\left(H_{\mathrm{e}}\right)$ for Scabiosa columbaria

\begin{tabular}{lcccccc}
\hline Population & $\mathrm{Sm}$ & $\mathrm{Bj}$ & $\mathrm{Kl}$ & $\mathrm{Bi}$ & $\mathrm{Gr}$ & $\mathrm{Ma}$ \\
\hline Means & & & & & & \\
Leaf number & 35.2 & 41.3 & 41.7 & 37.4 & 43.8 & 52.4 \\
Leaf area $\left(10^{3} \mathrm{~mm}^{2}\right)$ & 17.9 & 23.1 & 24.8 & 27.2 & 26.5 & 21.5 \\
Leaf length $\left(10^{3} \mathrm{~mm}\right)$ & 1.87 & 1.70 & 1.85 & 2.07 & 1.76 & 1.74 \\
Main stem height $(\mathrm{mm})$ & 665 & 756 & 1060 & 977 & 1066 & 731 \\
Maximum height $(\mathrm{mm})$ & 843 & 896 & 1347 & 1214 & 1306 & 976 \\
Head number & 134 & 165 & 226 & 182 & 289 & 211 \\
Flowering date & 27.7 & 35.8 & 34.2 & 33.8 & 40.6 & 29.1 \\
Flower size (mm) & 12.3 & 12.4 & 13.0 & 14.6 & 11.0 & 13.9 \\
Heritabilities & & & & & & \\
Leaf number & 0.108 & 0.177 & $0.753^{*}$ & 0.221 & 0.174 & $0.414^{*}$ \\
Leaf area & $0.386^{*}$ & 0.315 & $0.470^{*}$ & 0 & 0.184 & 0.129 \\
Leaf length & 0.098 & 0.154 & 0.176 & 0 & 0.078 & 0 \\
Main stem height & $0.447^{*}$ & 0.109 & 0.110 & 0 & 0.325 & $0.630^{*}$ \\
Maximum height & $0.677^{*}$ & 0.082 & $0.432^{*}$ & 0.147 & 0.360 & $0.880^{*}$ \\
Head number & $0.438^{*}$ & 0.098 & 0.091 & $0.405^{*}$ & 0.300 & 0.338 \\
Flowering date & $0.405^{*}$ & 0.198 & $0.450^{*}$ & 0.222 & 0.319 & $0.437^{*}$ \\
Flower size & $0.526^{*}$ & $0.557^{*}$ & 0.328 & 0.112 & $0.499^{*}$ & 0 \\
Average & 0.386 & 0.211 & 0.351 & 0.138 & 0.280 & 0.354 \\
$H_{\mathrm{e}}$ & 0.445 & 0.221 & 0.327 & 0.179 & 0.422 & 0.224 \\
\hline
\end{tabular}

Populations have been arranged according to increasing size.

*The $95 \%$ CI of the heritability does not overlap zero.

\section{Discussion}

\section{Within-population variation}

Population genetic theory of finite populations predicts a loss of variation as a result of inbreeding and random genetic drift (Falconer, 1989). Hence, given the small and disjunct populations of many rare, endangered species and the adaptive significance of heritable variation (Lande \& Barrowclough, 1987), numerous attempts have been made to estimate the level of genetic variation in populations of rare species (Schemske et al., 1994). Most of these studies have focused on allozymes or molecular marker genes, presumably under the assumption that levels of variation in single-locus characters also provide insights into levels of variation of polygenic characters. The validity of this assumption has been questioned (Lynch, 1996) and the present investigation provides no evidence for a strong association between marker gene diversity and quantitative genetic variation. Admittedly, it is possible that our study lacked the power to detect such relationships, given the large standard errors of most heritability estimates (Falconer, 1989) and the small number of allozyme loci scored, especially for $S$. canescens.
Despite a more than 100 -fold difference in population size, there was no tendency for small populations to possess lower levels of quantitative genetic variation than large populations: the highest average heritability was recorded for the smallest population in each species ( $\mathrm{Sm}$ and Häin Table 2a,b) and the heritability for leaf and flower size was significantly negatively correlated with population size in $S$. columbaria. That small populations can retain high levels of quantitative variation for ecologically important characters has also been demonstrated in other rare plant species, e.g. Senecio integrifolius (Widén \& Andersson, 1993). It is worth noting that $S$. columbaria and $S$. canescens also show nonsignificant relationships between population size and expected heterozygosity. Leaving aside the large standard errors of $H_{\mathrm{e}}$, this finding is in accord with data from other allozyme studies (Ellstrand \& Elam, 1993), including a recent investigation of $S$. columbaria in The Netherlands (Van Treuren et al., 1991).

The weak effect of population size on both heritability and expected heterozygosity has at least four possible causes. First, the sampling variance of these parameters is large, particularly for small populations (Lynch, 1988). Secondly, occasional long- 
Table 2(b) Population means, heritabilities and expected heterozygosities $\left(H_{\mathrm{e}}\right)$ for Scabiosa canescens

\begin{tabular}{|c|c|c|c|c|c|c|}
\hline Population & Hä & $\mathrm{Ve}$ & De & $\mathrm{Vi}$ & Yn & Åh \\
\hline \multicolumn{7}{|l|}{ Means } \\
\hline Leaf number & 33.3 & 26.7 & 36.3 & 26.3 & 27.1 & 27.9 \\
\hline Leaf area $\left(10^{3} \mathrm{~mm}^{2}\right)$ & 9.72 & 10.7 & 9.22 & 11.2 & 9.82 & 11.6 \\
\hline Leaf length $\left(10^{3} \mathrm{~mm}\right)$ & 1.28 & 1.50 & 1.25 & 1.28 & 1.37 & 1.36 \\
\hline Main stem height $(\mathrm{mm})$ & 564 & 593 & 559 & 525 & 581 & 602 \\
\hline Maximum height (mm) & 669 & 769 & 670 & 622 & 687 & 717 \\
\hline Head number & 89.8 & 97.8 & 104 & 70.4 & 66.5 & 77.0 \\
\hline Flowering date & 44.8 & 40.3 & 42.7 & 43.2 & 44.4 & 42.7 \\
\hline Flower size $(\mathrm{mm})$ & 9.16 & 11.1 & 11.0 & 10.7 & 10.8 & 11.0 \\
\hline \multicolumn{7}{|l|}{ Heritabilities } \\
\hline Leaf number & 0.009 & 0.002 & $0.500 *$ & $0.734 *$ & $0.411 *$ & $1.010^{*}$ \\
\hline Leaf area & $0.603^{*}$ & $0.672 *$ & $0.409 *$ & $0.988^{*}$ & $0.452 *$ & $0.583^{*}$ \\
\hline Leaf length & $0.548^{*}$ & 0.236 & 0.192 & $0.546^{*}$ & 0.212 & $0.570^{*}$ \\
\hline Main stem height & $0.608 *$ & 0.213 & 0.350 & $0.408 *$ & $0.610^{*}$ & 0.068 \\
\hline Maximum height & $0.691^{*}$ & 0 & $0.395 *$ & 0.327 & $0.778 *$ & 0.270 \\
\hline Head number & $0.414^{*}$ & 0 & 0.056 & $0.014^{*}$ & $0.713^{*}$ & $0.739 *$ \\
\hline Flowering date & $0.557^{*}$ & $1.49^{*}$ & $0.511 *$ & $0.418^{*}$ & 0.293 & 0.098 \\
\hline Flower size & $0.470^{*}$ & 0 & $0.677^{*}$ & $0.403^{*}$ & 0.107 & 0.176 \\
\hline Average & 0.488 & 0.327 & 0.386 & 0.480 & 0.447 & 0.439 \\
\hline$H_{\mathrm{e}}$ & 0.249 & 0.363 & 0.040 & 0.390 & 0.225 & 0.373 \\
\hline
\end{tabular}

Populations have been arranged according to increasing size.

*The $95 \%$ CI of the heritability does not overlap zero.

distance gene flow could diminish the effect of genetic drift and the loss of genetic variation in small populations (Ellstrand \& Elam, 1993). Thirdly, a subdivided population can maintain higher levels of genetic variation than a panmictic population of the same size (e.g. Goldstein \& Holsinger, 1992), a possible explanation of the unusually high heritabilities in the small Sm population, which shows higher levels of spatial structuring than other populations (pers. obs.). Finally, the level of genetic variation should be more strongly influenced by the long-term population size than by the current number of individuals, perhaps explaining the high heritabilities and the relatively high allozyme diversity in the small Hä population, for which historical evidence indicates a larger population size in the past ( $\mathrm{L}$. Knutsson, pers. com.).

Mechanisms that could explain the high heritability in small populations with low allozyme diversity (e.g. Bj, Table 2a) include microsite heterogeneity

Table 3 The level of population differentiation in phenotypic characters of Scabiosa, as determined by $Q_{\text {sт }}$ and its $95 \%$ confidence intervals (CI)

\begin{tabular}{|c|c|c|c|c|c|c|}
\hline \multirow[b]{3}{*}{ Leaf number } & \multicolumn{3}{|c|}{ S. columbaria } & \multicolumn{3}{|c|}{ S. canescens } \\
\hline & \multirow{2}{*}{$\frac{Q_{\mathrm{ST}}}{0.154}$} & \multicolumn{2}{|c|}{$\mathrm{CI}$} & \multirow{2}{*}{$\begin{array}{c}Q_{\mathrm{ST}} \\
0.114\end{array}$} & \multicolumn{2}{|c|}{$\mathrm{CI}$} \\
\hline & & -0.039 & 0.346 & & -0.043 & 0.271 \\
\hline Leaf area & 0.377 & 0.039 & 0.716 & 0.019 & -0.028 & 0.066 \\
\hline Leaf length & 0.526 & -0.024 & 1.076 & 0.088 & -0.044 & 0.220 \\
\hline Main stem height & 0.750 & 0.494 & 1.007 & 0.069 & -0.044 & 0.182 \\
\hline Maximum height & 0.570 & 0.245 & 0.895 & 0.104 & -0.041 & 0.250 \\
\hline Head number & 0.379 & 0.050 & 0.708 & 0.113 & -0.047 & 0.272 \\
\hline Flowering date & 0.380 & 0.055 & 0.706 & 0.041 & -0.040 & 0.122 \\
\hline Flower size & 0.485 & 0.146 & 0.824 & 0.217 & -0.036 & 0.469 \\
\hline
\end{tabular}


combined with local selection and/or genotype $\times$ environment interaction (Barton \& Turelli, 1989), and the conversion of nonadditive variance into additive variance after a bottleneck (Goodnight, 1988; Willis \& Orr, 1993).

\section{Genetic differentiation between populations}

Estimates of $Q_{\text {ST }}$ for $S$. canescens were similar to, or slightly lower than, the corresponding parameter for the allozyme markers $\left(F_{\mathrm{ST}}\right)$. Based on the wide overlap between confidence intervals, there is no reason to believe that the phenotypic characters are more strongly influenced by geographically varying selection than by random genetic drift in this species. As for $S$. columbaria, estimates of $Q_{\mathrm{ST}}$ always exceeded the allozymic $F_{\text {ST }}$ with significantly higher values for traits reflecting plant stature, indicating that diversifying selection has played a major role in shaping large-scale patterns of variation in this species, at least in southernmost parts of Sweden. This scenario is consistent with the weak association between genetic distances based on allozymes $\left(F_{\mathrm{ST}}\right)$ and quantitative characters $\left(Q_{\mathrm{ST}}\right)$, and may be particularly relevant for plant height, given the tendency for coastal plants ( $\mathrm{Sm}, \mathrm{Bj}$ and $\mathrm{Ma}$ ) to be of shorter stature than those representing more mesic inland localities ( $\mathrm{Kl}, \mathrm{Bi}$ and $\mathrm{Gr}$; Table 2a).

Podolsky \& Holtsford (1995) assessed patterns and levels of population differentiation in allozymes and a wide range of floral characters in the plant Clarkia dudleyana (Onagraceae). Most of the $Q_{\mathrm{ST}}$ values were similar to, or higher than, the estimate of $F_{\mathrm{ST}}$ based on allozymes, indicating that characters had been influenced by genetic drift or by selection for different optimum phenotypes in different populations. In a study of the conifer Pinus contorta ssp. latifolia, Yang et al. (1996) found the $Q_{\mathrm{ST}}$ values for specific gravity, stem diameter, stem height and branch length to be significantly higher than the allozymic $F_{\mathrm{ST}}$, and attributed these differences to diversifying selection, whereas the data for branch angle and branch diameter were consistent with the neutrality hypothesis. A recent study of the rare, endemic plant Silene diclinis (P. Waldmann, S. Andersson \& H. Prentice, unpubl. obs.) revealed a tendency for some traits to be less differentiated than allozymes, presumably because of unifying selection. When combined with genetic evidence from Scabiosa (this study), there is considerable variation in the extent to which marker genes provide a valuable overview of the genetic structure for quantitative characters.
Yang et al. (1996) reviewed the basic assumptions underlying comparative studies of population genetic structure. Implicit in the present investigation are the assumptions that the allozymes are selectively neutral and that different allozyme loci provide more or less independent information on singlelocus diversity. However, we cannot exclude the possibility that the genetic variances within populations have been overestimated because of nongenetic (maternal) effects, particularly for traits expressed early in the ontogeny, a factor that would lead to a downward bias in $Q_{\mathrm{ST}}$. Inclusion of variance arising from nonadditive gene interactions (dominance, epistasis) could also affect $Q_{\mathrm{ST}}$, but the detection of such effects would require a more complex crossing design. The partitioning of variation into additive and nonadditive genetic components (Falconer, 1989) will be the goal of a future study of $S$. canescens.

\section{Differences between species}

Rare species tend to have less allozyme diversity than more common and widespread taxa (Hamrick \& Godt, 1996), but there have been few attempts to examine whether rarity is associated with low levels of genetic variation in traits directly related to fitness. For example, Black-Samuelsson \& Andersson (1997) demonstrated more divergent genotypes in the broadly adapted Vicia dumetorum than in the rare and ecologically restricted $V$. pisiformis. Genetic data from the present investigation not only indicate low levels of population differentiation in the rare $S$. canescens, but also suggest that natural selection may be responsible for the extensive population divergence in $S$. columbaria. One interpretation of these findings is that $S$. columbaria is more responsive to local selection pressures, perhaps explaining why this species has a broader ecological amplitude than $S$. canescens.

\section{Acknow ledgements}

Thanks to Robert Podolsky and Michael Lynch for comments on the manuscript and to Rune Svensson, Sanna Björklund and Pär-Åke Jonsson for technical assistance. Financial support was provided by the World Wildlife Fund.

\section{References}

Ashton, G. C. AND BRAden, A. w. H. 1964. Serum $\beta$ globulin polymorphism in mice. Aust. J. Biol. Sci., 14, 248-254. 
BARTON, N. H. AND TURELli, M. 1989. Evolutionary quantitative genetics: How little do we know? Ann. Rev. Genet., 23, 337-370.

BLACK-SAMUELSSON, S. AND ANDERSSON, s. 1997. Reaction norm variation between and within populations of two rare plant species, Vicia pisiformis and $V$. dumetorum (Fabaceae). Heredity, 79, 268-276.

EFRON, B. AND TIBSHIRANI, R. 1986. Bootstrap methods for standard errors, confidence intervals and other methods of statistical accuracy. Stat. Sci., 1, 54-77.

ELlstrand, N. C. AND ElAM, D. R. 1993. Population genetic consequences of small population size: implications for plant conservation. Ann. Rev. Ecol. Syst., 24, 217-242.

FALCONER, D. S. 1989. Introduction to Quantitative Genetics, 3rd edn. Longman, Harlow.

FOLEY, P. 1992. Small population genetic variability at loci under stabilizing selection. Evolution, 46, 763-774.

Genstat 5. 1995. Release 3.2. Lawes Agricultural Trust. Rothamsted Experimental Station, Rothamsted, U.K.

GOLDSTEIN, D. B. AND HOLSINGER, K. E. 1992. Maintenance of polygenic variation in spatially structured populations: roles for local mating and genetic redundancy. Evolution, 46, 412-429.

GOODNIGHT, C. J. 1988. Epistasis and the effect of founder events on the additive genetic variance. Evolution, 42, 441-454.

GOUDET, J. 1995. FSTAT v-1.2: a computer program to calculate $F$-statistics. J. Hered., 86, 485-486.

HAMRICK, J. AND GODT, M. J. W. 1996. Conservation genetics of endemic plant species. In: Avise, J. C. and Hamrick, J. L. (eds) Conservation Genetics: Case Histories from Nature, pp. 471-501. Chapman and Hall, New York.

Kendall, M. AND StuART, A. 1969. The Advanced Theory of Statistics, vol. 1, Distribution Theory, 3rd edn. Griffin, London.

LANDE, R. 1988. Genetics and demography in biological conservation. Science, 241, 1455-1460.

LANDE, R. AND BARROWClOUgh, G. F. 1987. Effective population size, genetic variation, and their use in population management. In: Soulé, M. E. (ed.) Viable Populations for Conservation, pp. 87-123. Cambridge University Press, Cambridge.

LYNCH, M. 1988. Design and analysis of experiments on random drift and inbreeding depression. Genetics, 120, 791-807.

LYNCH, M. 1996. A quantitative-genetic perspective on conservation issues. In: Avise, J. C. and Hamrick, J. L. (eds) Conservation Genetics: Case Histories from Nature, pp. 471-501. Chapman and Hall, New York.

MANTEL, N. 1967. The detection of disease clustering and a generalized regression approach. Cancer Res., 27, 209-220.
PODOlSKy, R. H. AND HOLtSFORD, T. P. 1995. Population structure of morphological traits in Clarkia dudleyana I. Comparison of $F_{\mathrm{ST}}$ between allozymes and morphological traits. Genetics, 140, 733-744.

RAYMOND, M. AND ROUSSET, F. 1995. GENEPOP (Version 1.2): population genetics software for exact tests and ecumenicism. J. Hered., 86, 248-249.

SCHEMSKE, D. S., HUSBAND, B. C., RUCKELSHAUS, M. H., GOODWILliE, C., PARKER, I. M. AND BISHOP, J. G. 1994. Evaluating approaches to the conservation of rare and endangered plants. Ecology, 75, 584-606.

SPITZE, K. 1993. Population structure in Daphnia obtusa: quantitative genetic and allozymic variation. Genetics, 135, 367-374.

STORFER, A. 1996. Quantitative genetics: a promising approach for the assessment of genetic variation in endangered species. Trends Ecol. Evol., 11, 343-348.

SWOFFORD, D. L. AND SElANDER, R. B. 1989. BIOSYs-1. A computer program for the analysis of allelic variation in population genetics and biochemical systematics. Release 1.7. University of Illinois, Urbana, IL.

VAN TREUREN, R. AND BIJLSMA, R. 1992. Duplication of the structural gene for glucosephosphate isomerase and phosphogluconate dehydrogenase in Scabiosa columbaria and their phylogenetic implications in the Dipsacaceae. Biochem. Genet., 30, 99-109.

VAN TREUREN, R., BIJLSMA, R., OUBORG, N. J. AND KWAK, M. M. 1994. Relationships between plant density, outcrossing rates and seed set in natural and experimental populations of Scabiosa columbaria. J. Evol. Biol., 7, 287-302.

VAN TREUREN, R., BIJLSMA, R., VAN DELDEN, W. AND OUBORG, N. J. 1991. The significance of genetic erosion in the process of extinction. I. Genetic differentiation in Salvia pratensis and Scabiosa columbaria in relation to population size. Heredity, 66, 181-189.

WEIR, B. S. AND COCKERHAM, C. C. 1984. Estimating $F$-statistics for the analysis of population structure. Evolution, 38, 1358-1370.

WENDEL, J. F. AND WEEDEN, N. F. 1989. Visualization and interpretation of plant isozymes. In: Soltis, D. E. and Soltis P. S. (eds) Isozymes in Plant Biology, pp. 5-45. Chapman and Hall, London.

WIDÉN, B. AND ANDERSSON, s. 1993. Quantitative genetics of life-history and morphology in a rare plant, Senecio integrifolius. Heredity, 70, 503-514.

WILLIS, J. H. AND ORR, H. A. 1993. Increased heritability variation following population bottlenecks: the role of dominance. Evolution, 47, 949-957.

WRIGHT, s. 1951. The genetic structure of populations. Ann. Eugen., 15, 323-354.

YANG, R. C., YEH, F. C. AND YANCHUK, A. D. 1996. A comparison of isozyme and quantitative genetic variation in Pinus contorta ssp. latifolia by $F_{\mathrm{ST}}$. Genetics, 142, 1045-1046. 